\title{
Expansion of Cankers Caused by Leucostoma cincta on Sweet Cherry Trees
}

\author{
R. M. Barakat and D. A. Johnson, Department of Plant Pathology, Washington State University, Pullman 99164
}

\begin{abstract}
Barakat, R. M., and Johnson, D. A. 1997. Expansion of cankers caused by Leucostoma cincta on sweet cherry trees. Plant Dis. 81:1391-1394.

Wounds made in July 1987 and fresh pruning cuts made monthly from August 1989 to July 1990 on sweet cherry trees were inoculated with Leucostoma cincta. Infection occurred each month, with a higher percentage of wounds becoming infected during the spring and summer than during the winter months. Inoculation with conidia placed directly on wounds or inoculation with pruning shears contaminated with conidia and mycelia resulted in the same incidence and severity of cankers. Canker enlargement was related to increasing monthly temperature. Greatest canker enlargement usually occurred from April through August. The period of least canker enlargement occurred from October through January. The largest cankers resulted from inoculations in July, and the smallest cankers resulted from inoculations in November, December, and January. Canker expansion curves were significantly described by cubic or quadratic equations for inoculation made during 10 of 12 months.
\end{abstract}

Leucostoma canker (perennial canker, Cytospora canker, and Valsa canker) is a dieback disease of sweet cherry (Prunus avium L.) in Washington state (16) and of Prunus spp. throughout the world $(4,8,10,19,20)$. The disease is caused by two fungi, Leucostoma cincta (Fr.:Fr.) Höhn, (anamorph = Cytospora cincta (Sacc.)) and L. persoonii Höhn. (anamorph = C. leucostoma (Sacc.)). L. cincta predominates in central Washington $(2,16)$.

Leucostoma canker of sweet cherry in Washington state is characterized by dieback of tree branches, bark cankers, gummosis, and tree decline. Many perennial cankers originate at pruning wounds $(9,19)$. Infections at pruning cuts are potentially devastating because they often are located at points critical to the architecture of the tree (4). Other avenues of infection are injuries to bark caused by insects, machinery, and cold temperatures $(4,19)$. Healthy, intact bark of stone fruit trees is not invaded by Leucostoma spp. $(4,9,17)$. Removal of diseased, woody tree material from orchards and maintaining tree vigor are important control practices for Leucostoma canker $(6,9)$.

There is little information on the expansion of cankers after infection of sweet cherry trees by $L$. cincta. A previous study indicated that canker expansion was greatest during ambient spring temperatures

Corresponding author: D. A. Johnson

E-mail: djohnsn@wsu.edu

PPNS No. 0169, Department of Plant Pathology, Project 0678, College of Agriculture and Home Economics, Research and Extension Center, Washington State University, Pullman 99164.

Accepted for publication 15 August 1997.

Publication no. D-1997-0929-03R

(C) 1997 The American Phytopathological Society
(16). A knowledge of the seasonal development of cankers in sweet cherry trees may aid in determining time of year when diseased tree material can most efficiently be identified and removed. The purposes of this study were to quantify canker enlargement during different seasons, and to compare infection when initiated by contaminated pruning shears or a conidial suspension placed directly on the wound.

\section{MATERIALS AND METHODS}

Sweet cherry trees in two different orchards located at the Irrigated Agriculture Research and Extension Center (IAREC), near Prosser, Washington, were inoculated in July 1987 and in each month from August 1989 through July 1990. Trees inoculated in 1987 were sprinkle-irrigated from low-angled water emitters so that tree foliage was not directly wetted. Trees inoculated in 1989 through 1990 were irrigated with water pulled down furrows by gravity. Both orchards were planted on a sandy loam soil and were free of canker diseases.

In 1987, 2-year-old wood on 24 stems of 8 mature trees, cultivar Bing, were inoculated (3 stems/tree) with mycelium of isolate 247 of $L$. cincta. Isolate 247 was originally isolated from a canker margin of a diseased sweet cherry tree in a commercial orchard near Prosser, Washington. Stems were surface-disinfested with $70 \%$ ethanol and wounded with a staple gun (Arrow T50, Arrow Fastener Co., Inc., Saddle Brook, NJ). The staple gun was modified to include an Xpando T-50 pop rivet attachment (Arrow Fastener), from which the metal collar surrounding the steel shaft of the pop rivet had been removed. Two shots of the staple gun in a linear row created a 3- by 6-mm wound which was 5.5 $\mathrm{mm}$ deep. The wounds were filled with agar plugs from 48-h-old cultures of $L$. cincta grown on malt agar (Difco Laboratories, Detroit), and were then wrapped with several layers of Parafilm $M$ (American National Can Co., Greenwich, CT). The film was removed after 1 week. Stem diameter and canker width were measured at monthly intervals for 8 months. Percentages of stem circumference colonized for each monthly measurement were calculated (13). This was done by directly measuring the diameter of the stem with a caliper and calculating the stem circumference by multiplying the diameter by 3.14. Canker widths were measured with a ruler and the width was then divided by the stem circumference and multiplied by 100 .

Tissue samples, measuring approximately 15 by $25 \mathrm{~mm}$, from the margins of infected and healthy tissues of inoculated stems were cut from trees, washed in running water, and then the outer bark tissue was removed with a sterilized scalpel. Tissue segments, measuring approximately 5 by $2.5 \mathrm{~mm}$, were excised from the advancing margin of the infected bark or internal stem tissue. The excised segments were surface-disinfested for $1 \mathrm{~min}$ in $0.5 \%$ $\mathrm{NaOCl}$, rinsed in sterile distilled water, and then placed on potato-dextrose agar (Difco) or malt agar.

Near the 20th of each month, from August 1989 through July 1990, pruning cuts were made on 108 sweet cherry trees, cultivar Sam, that were in their third year of growth. Three treatments were imposed on fresh pruning cuts: (i) inoculation with a conidial suspension, (ii) inoculation with a pruning shear dipped into a conidial and mycelial suspension, and (iii) a non-inoculated control. Each treatment was replicated three times using separate trees for each treatment and replicate; three subsamples of each treatment were made on each tree.

Conidia for the 1989 and 1990 inoculations were obtained from pycnidia from dead cherry branches from a commercial cherry orchard (cv. Bing) near Prosser. Branches were cut into $10-$ to $15-\mathrm{cm}$ pieces, rinsed with cold tap water for 5 min, and then placed on a wet paper towel in a sealed plastic bag overnight. Extruded conidia were lifted with a sterile scalpel, suspended in sterile distilled water, and adjusted with a hemacytometer to a concentration of $1.0 \times 10^{8}$ conidia per $\mathrm{ml}$ water. The teleomorph of Leucostoma spp. is not commonly observed on $P$. avium in central Washington, and conidia were collected only from branches that did not contain ascostromata or observable colonies of other fungi or bacteria. 
The pruning shear was infested by dipping it into a beaker containing a suspension of conidia and mycelium. Conidia were obtained as previously described, and mycelium was scraped from a 5-day-old culture of $L$. cincta grown on Difco malt agar at $23^{\circ} \mathrm{C}$.

Pruning wounds were made with ethanol-disinfested shears the day of inoculation by cutting cherry branches (2- to $3-\mathrm{cm}$ diameter) about $50 \mathrm{~cm}$ from the union of the branch with a main stem. Approximately $2 \mathrm{ml}$ of inoculum was applied to the wounded surface. Simultaneous pruning and inoculation treatments were made with shears that had been dipped into the suspension of conidia and mycelium. Clean shears that were disinfested with ethanol were used to initiate pruning cuts for a non-inoculated control. After inoculation, all cuts were wrapped with successive layers of Parafilm and tape. The Parafilm and tape strips were removed 1 week after inoculation.

Length of cankers was measured and recorded monthly for 1 year after each monthly inoculation. At the end of the 12month period for each inoculation, cambium and xylem tissues at the margin of cankers were placed on malt agar to reisolate L. cincta. Canker expansion length over time in months was expressed by calculating the area under canker expansion curves as is done in determining area under disease progress curves (11).

Air temperature was measured at IAREC near Prosser, Washington at a height of $1.5 \mathrm{~m}$ above the soil surface with a hygrothermograph in 1987, and with a probe thermister (Model 107, Campbell Scientific, Inc., Logan, UT) in 1988 through 1991. Monthly mean temperatures from July 1987 through February 1988 were calculated for the inoculations made July 1987. Mean temperatures from the 20th of one month to the 19th of the next month were calculated from 20 August 1989 through 19 July 1991 for the inoculations made August 1989 to July 1990.

Infection was considered to occur if cankers developed and L. cincta was reisolated. Percentage of wounds infected,

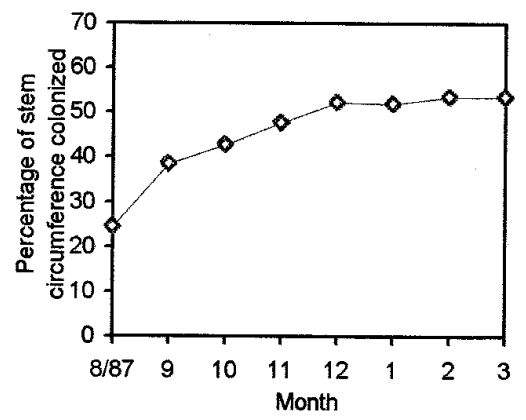

Fig. 1. Percentage of stem circumference colonized graphed over a 7-month period when wounds on sweet cherry trees were inoculated in July 1987 with Leucostoma cincta. final canker length, and area under the canker expansion curves were analyzed using analysis of variance. Monthly change in percentage of stem circumference colonized or canker length (dependent variable) and mean temperature for the corresponding time period (independent variable) was analyzed with linear regression (version 6.1, SAS PROC REG, SAS Institute Inc., Cary, NC). Canker expansion curves were analyzed with linear and curvilinear regression using SAS PROC GLM (version 6.04, SAS Institute Inc.). Values for canker length were modeled as a function of time after inoculation in months. Levels of the independent variable (months after inoculation) were standardized as deviations from the mean valve.

\section{RESULTS}

Percentage of stem circumference colonized from inoculations made in July 1987 increased through November and then stabilized through February 1988 (Fig. 1). Shape of the canker expansion curve over time was described by a quadratic equation. Monthly enlargement of cankers was significantly $(P=0.001)$ related to increase in mean monthly temperature. Coefficient of determination was 0.68 . Monthly mean temperatures were $21.0,21.3,18.5,12.0$, $6.2,-0.3,-0.3$, and $5.1^{\circ} \mathrm{C}$, respectively, for July 1987 though February 1988. Cankers developed and $L$. cincta was reisolated from all inoculated wounds. Cankers did not develop from wounds treated with sterile agar.

Percentage of successful inoculations, canker length, and shapes of canker expansion curves of inoculations made in 1989 and 1990 did not differ $(P>0.05)$ when conidia were applied directly, versus with shears, to wounds. Data from the two methods of inoculations were combined for analysis. Mean temperatures from the 20th of one month to the 19th of the next month from 20 August 1989 through 19 July 1991, respectively, were $17.8,14.1,8.5$, $1.9,2.2,2.8,6.8,8.5,13.0,16.1,23.5$, $23.8,19.5,13.8,8.1,3.4,-4.2,3.1,5.8$, $9.3,12.8,16.0$, and $20.1^{\circ} \mathrm{C}$.

The percentage of pruning wounds infected (cankers developed and L. cincta was reisolated) was $70 \%$ or greater from April through September, and 50\% or less from October through March (Table 1). Cankers did not develop and L. cincta was not reisolated from non-inoculated controls.

Monthly enlargement of cankers significantly increased $(P=0.0001)$ as mean monthly temperatures increased. Coefficient of determination was 0.31 for the 12 inoculation dates combined. The rate of canker enlargement was generally greatest from April through August (Fig. 2). The rate of canker enlargement was slow or did not increase during the late fall and winter months of October through January. Cankers from inoculations made in January, February, and March began to increase in length in April, May, and June, respectively, which was 3 months after each inoculation. Cankers from inoculations made in April, May, June, July, and August began to enlarge the month following inoculation. Cankers from inoculations in September, October, November, and December did not began to increase in size until the following late winter to early spring months of February through May (Fig. 2). The largest cankers resulted from those made in July, and the smallest cankers from those made in November, December, and January (Table 1).

Shapes of canker expansion curves for inoculations made in January, April, June, and November were best described by cubic equations. Curves for inoculations made in March, July, August, September,

Table 1. Frequency of wound infection, canker length, and area under the canker expansion curve (AUCEC), on sweet cherry trees inoculated with Leucostoma cincta monthly from August 1989 through July $1990^{\text {w }}$

\begin{tabular}{lccc}
\hline Month of inoculation & $\begin{array}{c}\text { Fresh wounds } \\
\text { infected }^{\mathbf{x}}\end{array}$ & Final canker length $(\mathbf{c m}) \mathbf{y}^{\mathbf{2}}$ & AUCEC $^{\mathbf{z}}(\mathbf{c m}-\mathbf{m o n t h})$ \\
\hline August & $72 \mathrm{abc}$ & $14.2 \mathrm{ab}$ & $74.0 \mathrm{ab}$ \\
September & $78 \mathrm{ab}$ & $12.7 \mathrm{bc}$ & $64.6 \mathrm{bc}$ \\
October & $50 \mathrm{bcd}$ & $9.5 \mathrm{cdef}$ & $43.2 \mathrm{~cd}$ \\
November & $39 \mathrm{~cd}$ & $5.2 \mathrm{f}$ & $26.8 \mathrm{~d}$ \\
December & $28 \mathrm{~d}$ & $8.3 \mathrm{def}$ & $41.6 \mathrm{~cd}$ \\
January & $50 \mathrm{bcd}$ & $6.5 \mathrm{ef}$ & $38.4 \mathrm{~cd}$ \\
February & $28 \mathrm{~d}$ & $7.8 \mathrm{def}$ & $49.5 \mathrm{bcd}$ \\
March & $39 \mathrm{~cd}$ & $7.0 \mathrm{ef}$ & $47.3 \mathrm{bcd}$ \\
April & $94 \mathrm{a}$ & $10.8 \mathrm{bcde}$ & $97.8 \mathrm{a}$ \\
May & $83 \mathrm{ab}$ & $12.0 \mathrm{bcd}$ & $102.1 \mathrm{a}$ \\
June & $94 \mathrm{a}$ & $12.0 \mathrm{bcd}$ & $94.8 \mathrm{a}$ \\
July & $89 \mathrm{a}$ & $17.4 \mathrm{a}$ & 94.9 \\
\hline
\end{tabular}

${ }^{\text {w }}$ Values are means of six replicates. Within a column, values with the same letter are not significantly different, $P=0.05$, according to Fisher's protected least significant difference.

${ }^{x}$ Percentage of inoculations that resulted in cankers from which $L$. cincta was reisolated.

y Only infected stems were included in the analysis.

${ }^{\mathrm{z}}$ Area under the curve made from graphing canker expansion measured in centimeters on the $\mathrm{Y}$ axis and time in months on the $\mathrm{X}$ axis. Values were calculated for inoculations that resulted in cankers from which $L$. cincta was reisolated. 
and October were described by quadratic equations. Canker expansion curves for inoculations made in February and December were best described by linear equations.

The areas under the canker expansion curves were largest when inoculations were made from April through August (Table 1). Final canker length showed the same trends as area; however, the longest cankers occurred when inoculations were made in July and August, and the largest areas occurred when inoculations were made in April through August (Table 1). Final canker length and areas for each inoculation were positively correlated $(\mathrm{r}=$ $0.79, P<0.01)$.

\section{DISCUSSION}

Cankers caused by L. cincta may progress perennially until tree branches or stems die. Rate of canker enlargement depends on seasonal temperature and host activity $(5,7)$. In Idaho, infection in plum and peach trees progressed most rapidly when both night and day temperatures were warm (7). In this study, canker enlargement in sweet cherry was significantly related to increasing mean monthly temperatures.

In Colorado, greatest canker enlargement occurred on peach during the spring and the least during the summer (12). In other locations, rate of canker expansion was more rapid during the winter, and less rapid during the summer when temperatures were high and callus formed around the canker $(4,5,8)$. In this study, maximum canker enlargement occurred during the summer months and was least during the winter months. This is in agreement with previous studies $(3,6,9,18)$. Bertrand and English (3) concluded that Leucostoma canker of French prune in California was primarily a summer disease. The same conclusion was reached by DeVay et al. while working on Leucostoma canker of President plum in California (6). Hyphae of Valsa ceratosperma invaded cortical and phloem tissues of apple bark in Japan very slowly during the dormant season. Canker development was most active in the early
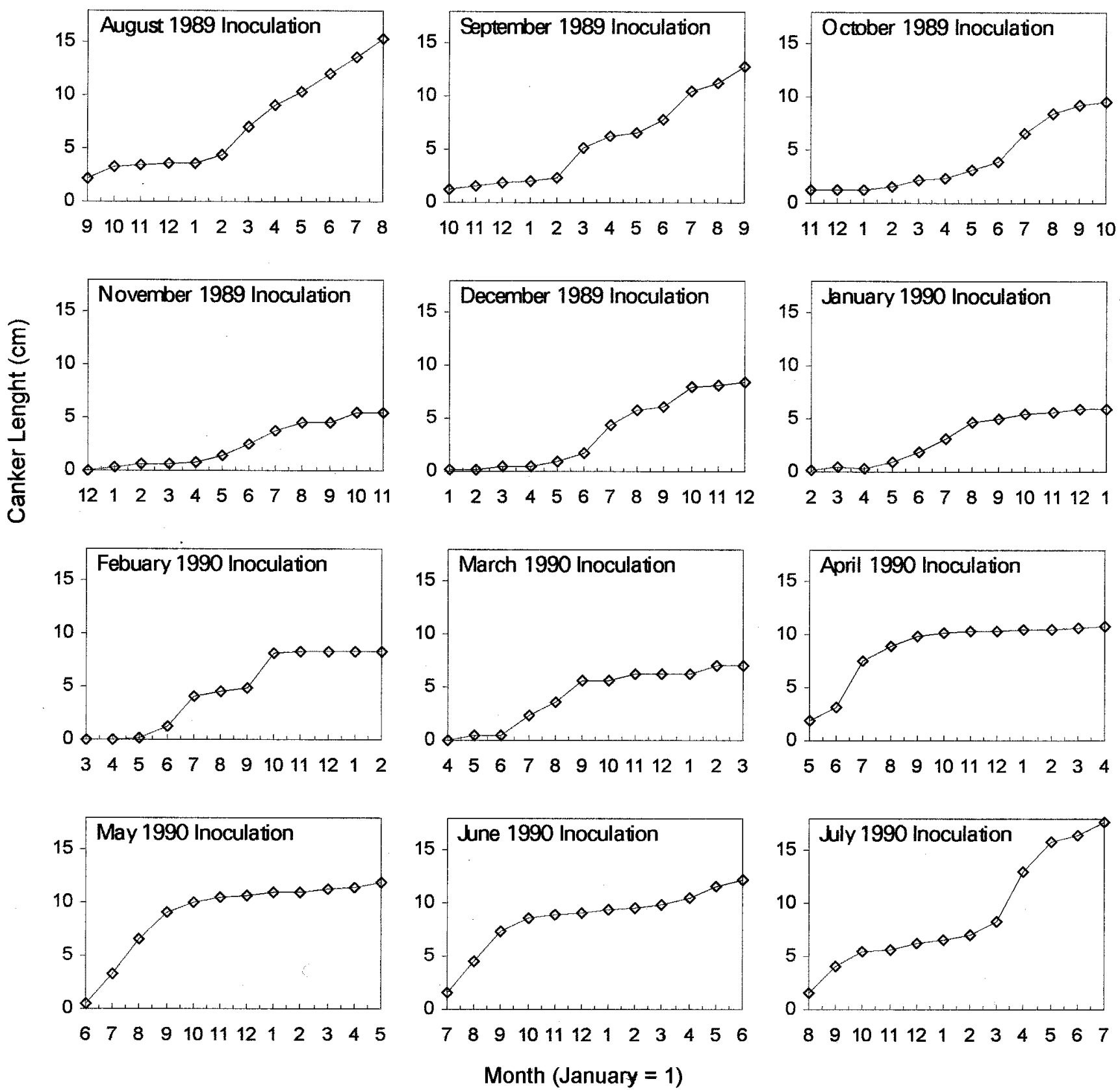

Fig. 2. Canker expansion curves when fresh pruning cuts on sweet cherry trees were inoculated monthly from August 1989 through July 1990 with Leucostoma cincta. 
growing season but slowed later in the growing season in response to wound cork layers developed by the host (18).

Helton (8) observed that inoculations on prune in the field at one time of the year often did not react like those made at other seasons. We found that time of year when inoculations were made influenced the shape of the canker expansion curves. The cubic and quadratic shapes of the canker expansion curves reflected the rapid canker enlargement during the warm summer months and a decrease during the winter. Warm temperatures and available carbohydrates probably play a role in canker expansion during summer. Host defense mechanisms (18) may have contributed to the delay in canker expansion observed in this study of wounds inoculated in September, October, and November 1989. The area under the canker expansion curves was also larger when inoculations were made in April through August. This may be a result of the fungus being able to establish a larger initial base of infected tissue during the warmer months than during the cooler winter months.

Fungal isolate and host vigor affects canker development $(3,8)$. Vigorously growing prune trees were found to be resistant and nonvigorous trees much less resistant to disease development when inoculated in California with L. persoonii (3). Sweet cherry trees used in this study were irrigated regularly and growth was considered to be vigorous. Cankers developed whenever wounds were inoculated on vigorously growing sweet cherry trees, emphasizing the importance of not only maintaining tree vigor but also preventing unnecessary wounds and reducing inoculum sources in and near orchards.

The area under the canker expansion curve was an adequate statistic for comparing canker expansion over time. Differences among month of inoculation were detected. Areas were significantly correlated with final canker length, but results utilizing the two statistics were somewhat different because the shapes of the canker curves for various months were different (Fig. 2).

Pruning cuts are a common infection site for infection by Leucostoma spp. $(4,9,14)$. Pruning shears contaminated with conidia and mycelia of L. cincta were demonstrated to efficiently spread the pathogen to pruning cuts on sweet cherry. Viable conidia of Leucostoma spp. have been found throughout the year in orchards $(2,15)$ and could contaminate pruning shears during pruning or be moved to fresh pruning cuts by splashing rain, sprinkler irrigation water, and insects (4).

Inoculations with mycelium and conidia collected from naturally infected branches produced similar cankers. Conidia of $L$. cincta are not readily produced on agar media and mycelial inoculum has been used in previous studies $(3,7,12,16)$. A concern of using naturally produced conidia as inoculum was that it may be contaminated with other microorganisms or ascospores of $L$. cincta which may have different requirements for infection than conidia (2). Tree branches from which inoculum was obtained were observed for the teleomorph, which was not found. Contaminants of other microorganisms were likely not a factor because infections occurred, typical disease symptoms developed, and $L$. cincta was later reisolated from induced cankers. An advantage of naturally produced conidia is that they are the infective unit in nature, and aggressiveness of the pathogen is not altered by storage. Naturally occurring inoculum in an orchard was used to determine seasonal susceptibility of wounds on peach trees (15).

Delaying pruning until late spring when warmer temperatures prevail has been suggested as a means of protecting fresh pruning cuts from infection, because of rapid wound healing and callus formation $(1,12,20)$. However, viable conidia of $L$. persoonii were obtained throughout the year, with the greatest quantities occurring during the summer in a peach orchard in Colorado (15). Conidia of $L$. cincta in sweet cherry orchards in Washington were exuded from pycnidia over a wide temperature range whenever moisture was present. Optimal exudation was at $20^{\circ} \mathrm{C}$ (2). Conidia in dried cirrhi survived dry periods at summer temperatures and infected wounded hosts when moisture became available (2). Furthermore, maximum canker expansion occurred from inoculations made during the summer in this study. In the winter months, the rate of wound healing is low but the availability of inoculum, the percentage of infection, and the expansion of cankers are less. Cankers on sweet cherry trees in central Washington are probably best identified and removed during dry periods from late summer to early winter. A large proportion of cankers will be evident at this time because cankers will have expanded, and visibility of stems and branches will be good because of the onset of fall leaf drop. Regional differences can greatly influence development of leucostoma canker; cultural practices that are beneficial for disease management in central Washington may not be satisfactory in other production areas.

The time of year when pruning healthy stems and branches of sweet cherry trees is most beneficial for management of Leucostoma canker, if there is such a seasonal period, is not known for central Washington. More information about such factors as duration of susceptibility of cuts, and frequency and duration of wet periods favorable for infection, during the course of the various seasons is needed to help determine the most beneficial season to prune. Because many factors influence infection and canker development, actual pruning experiments over several years will be needed to determine when sweet cherry trees can best be pruned to manage Leucostoma canker.

\section{LITERATURE CITED}

1. Alfieri, S. A., Seymour, C. P., Jr., and French, W. J. 1974. Cytospora canker of peach in Florida. Proc. Fla. State Hortic. Soc. 86:308-310.

2. Barakat, R. M., Johnson, D. A., and Grove, G G. 1995. Factors affecting conidial exudation and survival, and ascospore germination of Leucostoma cincta. Plant Dis. 79:1245-1248.

3. Bertrand, P. F., and English, H. 1976. Virulence and seasonal activity of Cytospora leucostoma and $C$. cincta in French prune trees in California. Plant Dis. Rep. 60:106:-110.

4. Biggs, A. R. 1989. Integrated approach to controlling Leucostoma canker of peach in Ontario. Plant Dis. 73:869-874.

5. Chilton, J. E. 1955. Cytospora apple canker disease. N. Mex. Agric. Exp. Stn. Press Bull. 1138.

6. DeVay, J. E., Gredts, M., English, H., and Lukezic, F. L. 1974. Controlling Cytospora canker in President plum orchards of California. Calif. Agric. 28(12):12-14.

7. Helton, A. W., and Konicek, D. E. 1961 Effects of selected Cytospora isolates from stone fruits on certain stone fruit varieties. Phytopathology 51:152-157.

8. Helton, A. W., and Mosiey, J. A. 1955. Cytospora damage in Idaho prune orchards. Plant Dis. Rep. 39:931-943.

9. Hildebrand, E. M. 1947. Perennial peach canker complex in New York, with methods of control. Cornell Univ. Agric. Exp. Stn. Mem. 276:45-61

10. James, W. C., and Davidson, T. R. 1971 Survey of peach canker in the Niagara Peninsula during 1960-1970. Can. Plant Dis. Surv. 51:148-153.

11. Johnson, D. A., and Wilcoxson, R. D. 1979. Inheritance of slow rusting of barley infected with Puccinia hordei and selection of latent period and number of uredia. Phytopathology 69:145-151.

12. Jones, A. C., and Luepschen, N. S, 1971. Seasonal development of Cytospora canker on peach in Colorado. Plant Dis. Rep. 55:314-317.

13. Kessler, K. J., Jr. 1978. Measurement of can kers on small woody stems. Eur. J. For. Pathol. 8:184-186.

14. Luepschen, N. S., Hetherington, J. E., Stahl, F. J. and Mowrer, K. E. 1979. Cytospora canker of peach trees in Colorado: Survey of incidence, canker location and apparent infection courts. Plant Dis. Rep. 63:685-687.

15. Luepschen, N. S., and Rohrbach, K. G. 1969. Cytospora canker of peach trees: spore availability and wound susceptibility. Plant Dis Rep. 53:869-872.1.

16. Regner, K. M., Johnson, D. A. and Gross, D. C. 1990. Etiology of canker and dieback of sweet cherry in Washington State. Plant Dis. 74:430-433.

17. Rohrbach, K. G., and Luepschen, N. S. 1968. Environmental and nutritional factors affecting pycnidiospore germination of Cytospora leucostoma. Phytopathology 58:1134-1138.

18. Tamura, O., and Saito, I. 1982. Histopathological changes of apple bark infected by Valsa ceratosperma (Tode ex Fr.) Marre during dormant and growing periods. Ann. Phytopathol. Soc. Jpn. 48:4900-498.

19. Willison, R. S. 1937. Peach canker investigation, III. Further notes on incidence, contributing factors, and control measures. Can. J Res. Sect. C. Bot. Sci. 15:324-339.

20. Wilson, C. L., Miller, S. S., Otto, B. E., and Eldridge, B. J. 1984. Pruning technique affects dieback and Cytospora infection in peach trees. HortScience 19:251-253. 